\title{
An epidemiologic comparison of acute and overuse injuries in high school sports
}

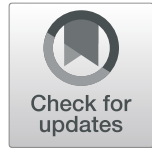

Erin E. Ritzer ${ }^{1,2}$, Jingzhen Yang ${ }^{1,3}$, Sandhya Kistamgari ${ }^{1}$, Christy L. Collins ${ }^{4}$ and Gary A. Smith ${ }^{1,3,5^{*}}$

\begin{abstract}
Background: Acute and overuse injuries affect millions of high school athletes annually and a better understanding of differences between these injuries is needed to help guide prevention, treatment, and rehabilitation strategies. This study compares acute and overuse injuries using a nationally representative sample of high school athletes.

Methods: Injuries among United States high school athletes participating in 5 boys' sports (football, soccer, basketball, wrestling, baseball) and 4 girls' sports (soccer, volleyball, basketball, softball) reported in the High School $\mathrm{RIO}^{\mathrm{TM}}$ surveillance system during the 2006-07 through 2018-19 school years were classified as acute or overuse. National estimates and injury rates were calculated.

Results: Of 17434646 estimated injuries, $92.0 \%$ were acute and $8.0 \%$ were overuse. The acute injury rate was higher than the overuse injury rate among both male (Rate Ratio [RR] 16.38, $95 \%$ Cl: 15.70-17.10) and female (RR 8.14, $95 \%$ Cl: 7.71-8.60) athletes. The overuse injury rate per 10,000 athlete exposures among female athletes (1.8) was slightly higher than among males (1.4). The rate of acute injury compared with the rate of overuse injury was higher during competition (RR 32.00, 95 \% Cl: 29.93-34.22) than practice (RR 7.19, $95 \%$ Cl: 6.91-7.47). Boys' football contributed the most acute (42.1\%) and overuse (23.7\%) injuries among the 9 sports. Among female sports, girls' soccer contributed the most acute (15.6\% of all acute injuries) and overuse (19.4\% of all overuse injuries) injuries. The lower extremity was most commonly injured in acute (48.9\%) and overuse (65.9\%) injuries. Ligament sprain $(31.7 \%)$ and concussion (21.0\%) were the most common acute injury diagnoses, while muscle strain (23.3\%) and tendonitis (23.2\%) were the most common overuse injury diagnoses. Compared with acute injuries, overuse injuries were more likely to result in time loss from sports participation of $<1$ week among both boys and girls and across most sports. Acute injuries were more likely than overuse injuries to cause a time loss of 1-3 weeks or medical disqualification from sports participation.
\end{abstract}

Conclusions: Acute and overuse injuries display many differences that provide opportunities for data-informed athlete preparation, treatment, and rehabilitation, which may reduce injuries and improve injury outcomes in high school athletics.

Keywords: High School Athletes, Gender-Comparable Sports, Injury Reporting

\footnotetext{
* Correspondence: Gary.Smith@nationwidechildrens.org

${ }^{1}$ Center for Injury Research and Policy, Abigail Wexner Research Institute at Nationwide Children's Hospital, Columbus, OH, USA

${ }^{3}$ Department of Pediatrics, The Ohio State University College of Medicine, Columbus, OH, USA

Full list of author information is available at the end of the article
}

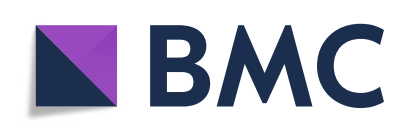

(- The Author(s). 2021 Open Access This article is licensed under a Creative Commons Attribution 4.0 International License, which permits use, sharing, adaptation, distribution and reproduction in any medium or format, as long as you give appropriate credit to the original author(s) and the source, provide a link to the Creative Commons licence, and indicate if changes were made. The images or other third party material in this article are included in the article's Creative Commons licence, unless indicated otherwise in a credit line to the material. If material is not included in the article's Creative Commons licence and your intended use is not permitted by statutory regulation or exceeds the permitted use, you will need to obtain permission directly from the copyright holder. To view a copy of this licence, visit http://creativecommons.org/licenses/by/4.0/. The Creative Commons Public Domain Dedication waiver (http://creativecommons.org/publicdomain/zero/1.0/) applies to the data made available in this article, unless otherwise stated in a credit line to the data. 


\section{Background}

Approximately 7.9 million athletes participated in high school sanctioned sports during the 2018-2019 school year, which is the third highest annual number of participants reported since the first National Federation of State High School Associations survey was implemented in 1971 (Participation 2019). Youth sports provide many benefits, including opportunities to improve social skills, self-esteem, and general physical fitness; yet sports participation also has drawbacks, including exposure to stressful situations and the risk of injury (Merkel and Merkel 2013). It has been well established that injuries during developmental years can have lasting effects on the health of athletes. With participation numbers rising, the consequences of injury, both immediate and longterm, will continue to place a significant burden on the healthcare system.

Using data collected from various injury reporting systems, existing studies have analyzed sports-related injuries at individual universities, groups of high schools, or within specific cohorts of athletes, which limit their ability to establish patterns that can be generalized across larger populations (Cuff et al. 2010; Liller et al. 2019; Lundberg Zachrisson et al. 2020; Yang et al. 2012). Other studies have been limited to a certain sport, type of injury, or body part, also reducing their generalizability (Badgeley et al. 2013; Ingram et al. 2008; Kerr et al. 2011; Saper et al. 2018; Swenson et al. 2010; Xiang et al. 2014; Yard et al. 2008; Yard et al. 2008). High School Reporting Information Online $\left(\mathrm{RIO}^{\mathrm{m}}\right)$ is currently the largest sportsrelated injury surveillance system that uses a nationally representative sample of United States (US) high school athletes. While it has been used in many peerreviewed publications, few have studied overuse injuries (Cuff et al. 2010; Kerr et al. 2018; Rechel et al. 2008; Schroeder et al. 2015). To-date, no studies have directly compared characteristics of acute and overuse injuries using a nationally representative database.

This study compared acute and overuse injuries using a nationally representative sample of US high school athletes participating in 5 boys' sports (football, soccer, basketball, wrestling, baseball) and 4 girls' sports (soccer, volleyball, basketball, softball) using data obtained from RIO $^{\text {max }}$. Specifically, this study investigated differences in frequency and rates of injury as well as injury characteristics (i.e., body site, diagnosis, recurrence, and time loss from sports participation) between acute and overuse injuries while also considering the role that gender plays in these differences. Study findings fill a gap in our knowledge about these injuries that will help guide prevention, treatment, and rehabilitation strategies.

\section{Methods}

\section{Source of Data}

Study data were obtained from the national high school sports-related injury surveillance system, $\mathrm{RIO}^{\mathrm{Tm}}$. $\mathrm{RIO}^{\mathrm{in}}$ data collection methods have been detailed previously (Kerr et al. 2018; Rechel et al. 2008). Briefly, starting in the 2005-06 school year, high schools with at least one certified athletic trainer (AT) affiliated with the National Athletic Trainers' Association were invited to participate in the surveillance system. Onehundred high schools were chosen randomly from 8 strata, based on geographic region and school size, to form a nationally representative sample of high school athletes participating in 9 common high school sports; the sample has been updated annually. RIO ${ }^{\mathrm{ms}}$ also includes data on injuries and exposures from additional sports based on convenience sampling; these injuries were not included in this study because they are unable to be used to calculate national estimates. A weighting algorithm was used to generate national injury estimates for the 9 sports included in this study. ATs from participating high schools reported injuries and athlete exposures (AEs) weekly to $\mathrm{RIO}^{\mathrm{mix}}$. For each injury, ATs reported details on injured athletes' demographics, sport, injury circumstances including whether it was a new or recurrent injury, mechanisms of onset, preliminary diagnosis, treatment(s) received, and return to play/medical disqualification information. Medical disqualification is defined as discontinuation of an athlete's participation for a season or a career within the sport in which the injury occurred. ATs were able to update injury reports within the database if new information became available, including, when appropriate, updated diagnoses from physicians or additional details about the injury.

\section{Definitions of Injury and Athlete Exposure}

In this study, an injury satisfied all these criteria: (1) occurred due to participation in an organized high school practice or competition, (2) required medical attention, and (3) resulted in a time loss from participation of at least 1 day beyond the day the injury occurred, or any fracture, concussion, or dental injury, regardless of whether it restricted an athlete's participation. An AE was defined as one athlete participating in one practice or one competition.

\section{Study Population and Gender-Comparable Sports}

This study included athletes injured while participating in 9 sports (boys' football, boys' and girls' soccer, girls' volleyball, boys' and girls' basketball, boys' wrestling, boys' baseball, and girls' softball) from the 2006-07 through 2018-19 school years. Data from the 2005-06 
school year were not included because the database did not include "overuse/chronic" as an option for a basic injury mechanism during that year. Six sports were considered gender-comparable based on similar rules or play tactics: boys' and girls' soccer, boys' and girls' basketball, and boys' baseball and girls' softball (Shanley et al. 2011).

\section{Categorization of Acute and Overuse Injuries}

Injuries were categorized as acute or overuse using the algorithm outlined in the flowchart in Fig. 1. Overuse injury has been previously characterized by (1) a mechanism of gradual onset, and (2) an underlying pathogenesis of repetitive microtrauma (Roos et al. 2014). In the current study, overuse injuries included those resulting from repetitive exposure or an overuse/chronic mechanism, and acute injuries included those caused immediately by a specific event. Injuries were first categorized as overuse or acute based on reported injury diagnosis. Any injury that was reported by an AT as being due to an overuse/ chronic mechanism was categorized as overuse. If an injury had a diagnosis that initially was considered to be in the acute injury category but was reported to have an overuse/chronic mechanism, then it was recategorized as an overuse injury.

\section{Categorization of Injuries by Body Site and Diagnosis}

The injured body part was grouped into 5 categories: (1) head/face/neck, (2) trunk, (3) upper extremity,
(4) lower extremity, and (5) other. The "other" body site category included injuries to male genitalia and body parts listed as "other" in RIO ${ }^{\mathrm{Tm}}$. Injury diagnoses were grouped by their overall diagnosis. For example, injuries coded as ligament sprain, ligament sprain (complete tear), ligament sprain (incomplete tear), and ligament sprain (unknown severity) were grouped as ligament sprain (any severity). "Other unspecified" was used to describe an injury diagnosis reported by ATs as "other," which prompted the ATs to provide more information for an unlisted or unusual diagnosis in $\mathrm{RIO}^{\mathrm{m}}$. The "other specified" category included all diagnoses that were selectable at data entry but were not among the top 10 most common diagnoses.

\section{Statistical Analysis}

Data were analyzed using IBM SPSS Statistics for Windows, Version 26 (Armonk, NY: IBM Corp) and SAS 9.4 (SAS Institute, Inc, Cary, NC). Sampling weights provided by $\mathrm{RIO}^{\mathrm{m}}$ were used to calculate national estimates. Descriptive statistics included national estimates and proportions with $95 \%$ confidence intervals (CIs). Poisson regression was used to estimate the rate ratio (RR) using the rate of overuse injury as the denominator. Injury rates and RRs were expressed as the ratio of unweighted injury counts per 10,000 AEs. All other calculations, including injury proportion ratios (IPRs), used weighted data. The level of significance was $\alpha=0.05$ for all analyses.

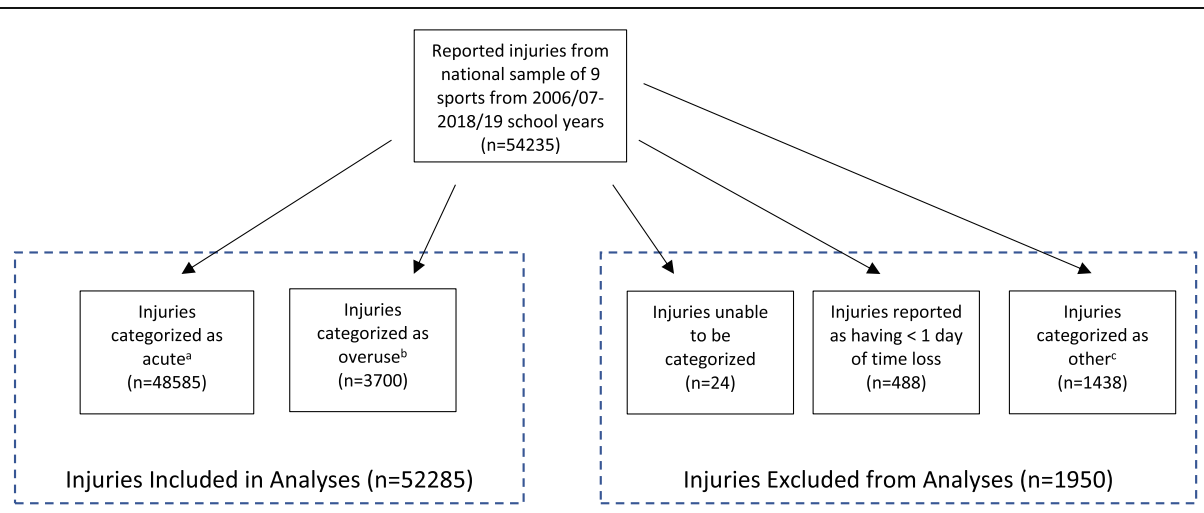

Fig. 1 Flowchart of Classification of Injuries. ${ }^{a}$ The following types of injuries were categorized as acute injuries: abrasion; concussion; contusion; dislocation; fracture; hemorrhage; hernia; hyperextension; internal injury (non-hemorrhage); laceration; ligament sprain (complete tear, incomplete tear, severity unknown); muscle strain (complete tear, incomplete tear, severity unknown); tendon strain (complete tear, incomplete tear, severity unknown); nerve injury; separation; torn cartilage; avulsion; multiple injuries; and subluxation. However, if injuries of these types were reported to be due to an overuse/chronic or illness mechanism, then they were not included in the acute category; they were categorized as detailed below.

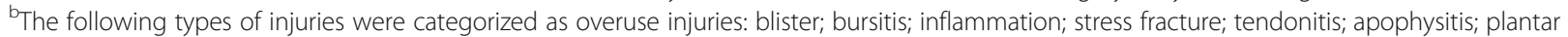
fasciitis; shin splints; and spondylolysis AND/OR any injury reported to be due to an overuse/chronic mechanism. ${ }^{~}$ The following types of injuries were categorized as other injuries: burn; dehydration; heatstroke/heat; infection (including skin infection); frostbite/cold related; cardiac event (acute); chronic disease/trait; respiratory event; heat illness/injury; and mental health concern AND/OR any injury reported to be due to an illness, other, or unknown mechanism 
An example of a RR calculation follows:

$$
\begin{aligned}
R R= & {[(\text { Number of acute injuries in } 2006-07 \text { school year }} \\
& / \text { Number of AEs in } 2006-07 \text { school year }) \times 10000] \\
& \div[\text { (Number of overuse injuries in } 2006-07 \text { school year } \\
& / \text { Number of AEs in } 2006-07 \text { school year }) \times 10000]
\end{aligned}
$$

An example of an IPR calculation follows:

$$
\begin{aligned}
& \text { IPR }=[(\text { Number of acute boys' football injuries resulting in } \\
& \text { medical disqualification / Total number of acute boys' football } \\
& \text { injuries }) \times 100] \div[(\text { Number of overuse boys' football injuries } \\
& \text { resulting in medical disqualification / Total number of overuse } \\
& \text { boys' football injuries }) \times 100]
\end{aligned}
$$

\section{Results}

\section{Injury Frequency and National Estimates}

From the 2006-07 through 2018-19 school year, 52285 injuries were reported, which represent an estimated 17 434646 injuries (95\% CI: $17 \quad 311 \quad 184-17 \quad 558$ 108) among high school athletes nationally, who participated in the 9 sports included in this study (Table 1). Most $(92.0 \%, n=16039385)$ of these injuries were acute, while the remaining $8.0 \%$ were overuse ( $n=1395$ 261). Overall, male athletes sustained $69.8 \%$ of acute, $55.9 \%$ of overuse, and $68.7 \%$ of total injuries. However, for the gender-comparable sports, female athletes accounted for most acute $(54.6 \%)$, overuse (56.1\%), and total (54.8\%) injuries.

While boys' football accounted for the most acute $(42.1 \%)$ and overuse (23.7\%) injuries among the 9 sports, boys' baseball contributed the fewest (3.4\%) acute injuries and boys' wrestling the fewest overuse injuries (3.5\%). Among female sports, girls' soccer accounted for the most acute $(15.6 \%$ of all acute injuries) and overuse (19.4\% of all overuse injuries) injuries, while girls' volleyball accounted for the least acute injuries ( $4.1 \%$ of all acute injuries) and girls' basketball the least overuse injuries $(7.3 \%$ of all overuse injuries).

The number of acute injuries increased slightly with increasing number of years in high school, with $23.3 \%$ of acute injuries occurring among freshmen, $25.3 \%$ among sophomores,

$25.4 \%$ among juniors, and $26.0 \%$ among seniors; however, this increase was not statistically significant $(\mathrm{p}$ > 0.05). The number of overuse injuries showed no relationship with year in school, with $25.8 \%, 24.5 \%, 25.4 \%$, and $24.3 \%$ occurring in freshman through senior years, respectively.

\section{Body Site and Diagnosis of Injuries}

Most acute $(48.9 \%)$ and overuse injuries $(65.9 \%)$ were to the lower extremities. The head/face/neck accounted for $25.6 \%$ of acute injuries and $0.9 \%$ of overuse injuries (Fig. $2 \mathrm{~A}$ and 2B). Among acute injuries, ligament sprains were the most common (31.7\%), followed by concussions $(21.0 \%)$, muscle strains $(12.2 \%)$, and contusions (11.9\%) (Fig. 2 C). Among overuse injuries, muscle strains $(23.3 \%)$ and tendonitis $(23.2 \%)$ were the most common (Fig. 2D).

\section{Injury Rates and Rate Ratios}

Overall, the rate of acute injury (19.2 per 10,000 AEs) was approximately 13 times (RR: 13.12, $95 \%$ CI: $12.69-$ 13.57) higher than the rate of overuse injury (1.5 per 10 , $000 \mathrm{AEs}$ ) (Table 2). When comparing gender differences across all 9 sports, males had a higher rate of acute injury (23.6 per 10,000 AEs) than females (14.9 per 10,000 AEs) (RR: 1.58, $95 \%$ CI: 1.54-1.61) and females had a higher rate of overuse injury (1.8 per 10,000 AEs) than males (1.4 per 10,000 AEs) (RR: 1.28, $95 \%$ CI: 1.19 1.36). Male athletes were about 16 times (RR: 16.38 , $95 \%$ CI: 15.70-17.10) and female athletes were about 8 times (RR: 8.14, $95 \%$ CI: 7.71-8.60) more likely to sustain an acute injury than an overuse injury. However, when comparisons were made within gendercomparable sports, female athletes had a higher rate of both acute (16.8 per 10,000 AEs; RR: $1.33,95 \% \mathrm{CI}$ : 1.29-1.36) and overuse (2.0 per 10,000 AEs; RR: 1.44 , $95 \%$ CI: 1.32-1.57) injuries than males (acute 12.7 and overuse 1.4 per 10,000 AEs), and the likelihood of acute injury to overuse injury among male athletes (RR: 9.30, $95 \%$ CI: 8.71-9.93) and female athletes (RR: 8.56, $95 \%$ CI: 8.05-9.10) was similar.

When comparing all 9 sports, boys' football had the highest rate (37.3 per 10,000 AEs) and boys' baseball had the lowest rate of acute injuries (7.7 per 10,000 AEs), while girls' soccer had the highest rate (2.3 per 10,000 AEs) and both boys' basketball and boy's wrestling had the lowest rate of overuse injuries (1.0 per 10,000 AEs each). Compared with overuse injuries, the likelihood of acute injuries was highest for boys' football (RR: 22.43, 95 \% CI: 21.09-23.86), followed by boy's wrestling (RR: 19.97, $95 \%$ CI: 17.28-23.09) and boys' basketball (RR: 14.65, 95 \% CI: 12.94-16.59).

When comparing only the four female sports, soccer had the highest rate of acute injury (22.3 per 10,000 $\mathrm{AEs}$ ) and highest RR of acute to overuse injury (RR: 9.85, $95 \%$ CI: 8.95-10.86). Volleyball had the lowest rates of acute (9.9 per 10,000 AEs) and overuse (1.5 per 10,000 AEs) injury, and softball had the lowest RR of acute to overuse injury (RR: 5.25, 95 \% CI: 4.65-5.93).

The rate of acute injury per 10,000 AEs was higher during competition (43.8) than practice (11.9) (RR: 3.70, 
Table 1 Reported Number and National Estimates of Acute and Overuse Injuries by Year, Gender, Sport, and Exposure Type

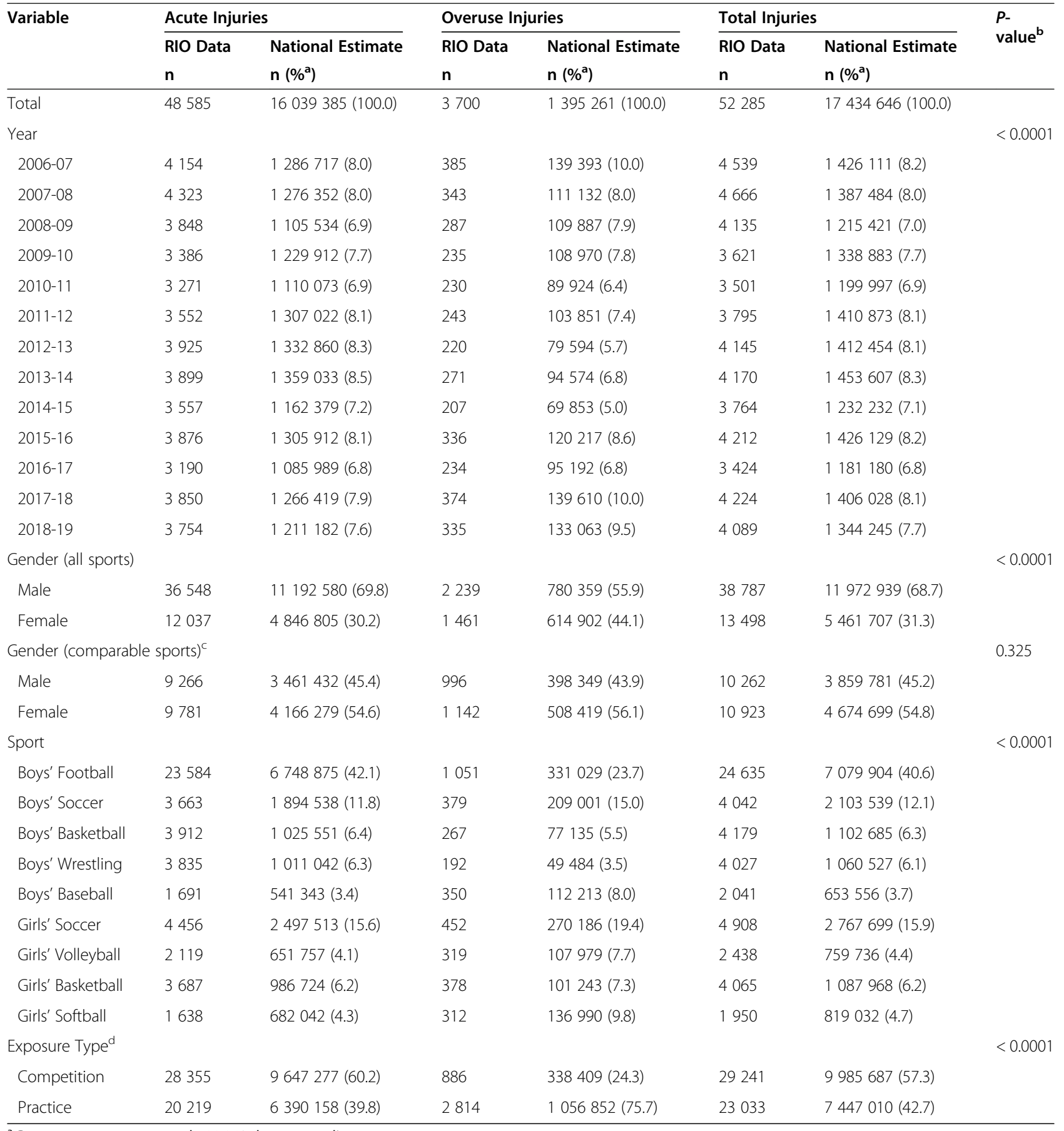

${ }^{a}$ Percentages may not equal $100.0 \%$ due to rounding

${ }^{\mathrm{b}} P$-values were based on Pearson chi-square comparing the frequencies of national estimates

'Comparable sports are boys' and girls' soccer, boys' and girls' basketball, boys' baseball and girls' softball

dexposure types "Other" $(n=10)$ and "Performance" $(n=1)$ were excluded from p-value analysis

$95 \%$ CI: 3.63-3.76), while practice had a higher rate of overuse injury (1.7) than competition (1.4) (RR: 1.20, $95 \%$ CI: 1.11-1.25). The risk of acute injuries compared with that of overuse injuries was higher during competition (RR: $32.00,95 \%$ CI: 29.93-34.22) than during practice (RR: 7.19, 95 \% CI: 6.91-7.47).

\section{New Versus Recurrent Injuries}

Most (90.3\%) acute injuries were new injuries, while $81.6 \%$ of overuse injuries were new (IPR: $1.11,95 \% \mathrm{CI}$ : 1.09-1.13). Recurrent injuries accounted for $9.7 \%$ of acute injuries, while $18.6 \%$ of overuse injuries were recurrent (IPR: 0.52, $95 \%$ CI: 0.47-0.57). 

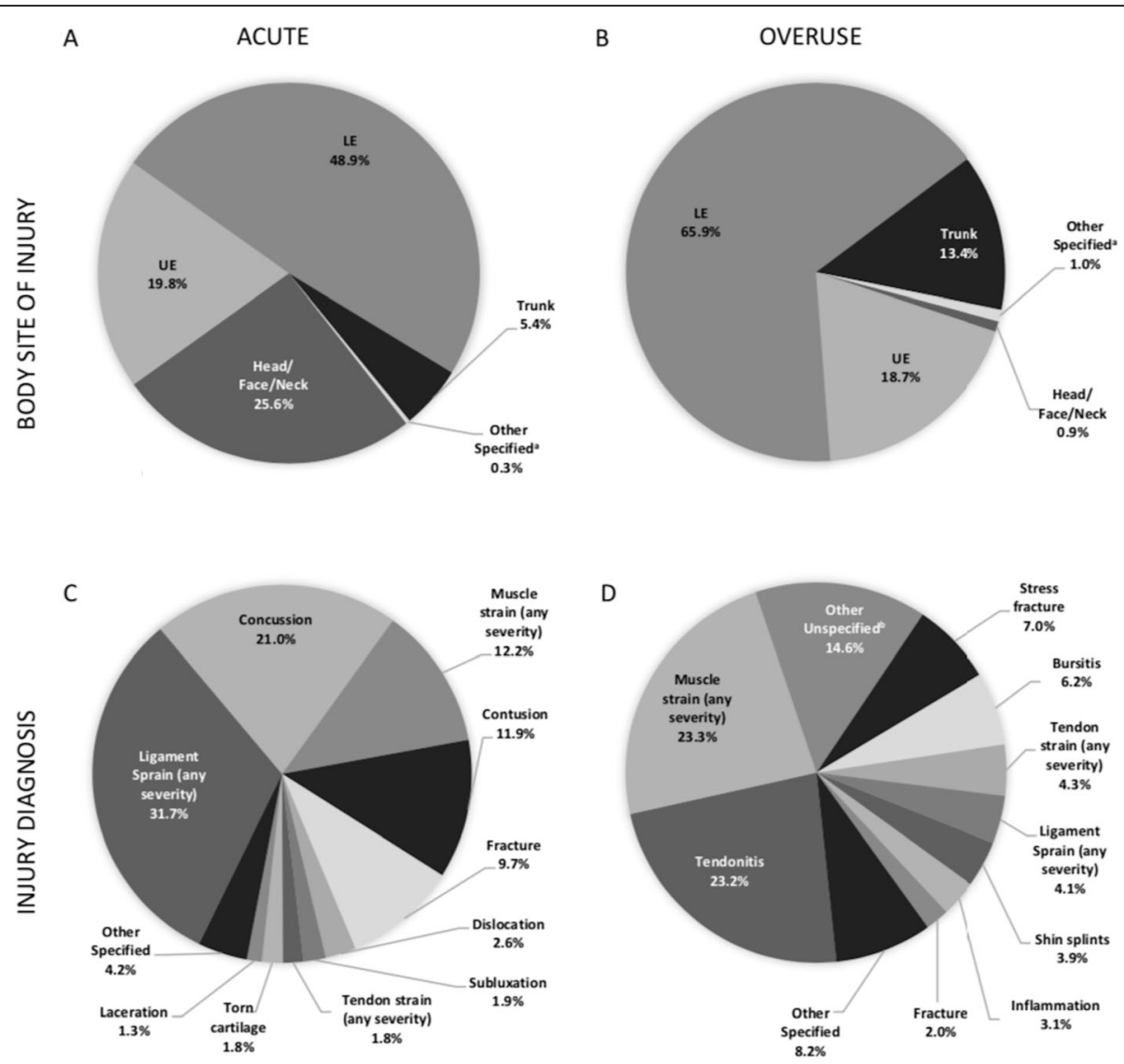

Fig. 2 Body Site and Diagnosis of Acute and Overuse Injuries. A shows the body sites of acute injuries. B shows the body sites of overuse injuries. "O"Other specified" indicates injuries coded as "other" and "male genitalia". C shows the top 10 diagnoses of acute injuries, with remaining diagnoses shown as "other specified". D shows the top 10 diagnoses of overuse injuries, with remaining diagnoses shown as "other specified". bSee methods section for description of "other unspecified"

\section{Time Loss}

Compared with overuse injuries, acute injuries were less likely to result in time loss from sports participation of $<1$ week overall (IPR: 0.70, $95 \%$ CI: $0.68-0.74$ ). This finding held true for both boys and girls and for all sports, except boys' baseball (IPR: 0.94, $95 \%$ CI: 0.811.10) (Table 3). Overall, acute injuries were more likely than overuse injuries to cause time loss of 1-3 weeks (IPR: 1.25, $95 \%$ CI: 1.16-1.34), > 3 weeks (IPR: 1.30, $95 \%$ CI: 1.10-1.52), or medical disqualification (IPR: 1.75, 95 \% CI: 1.43-2.14). This was also true among both male and female athletes, except males for $>3$ weeks of time loss (IPR: 1.10, 95 \% CI: 0.92-1.32). When considering only gender-comparable sports, female athletes were more likely to be medically disqualified due to an acute versus an overuse injury (IPR: 2.43 , 95 \% CI: $1.59-$ 3.72), while males demonstrated no difference in the proportion of medical disqualification (IPR: 1.51, $95 \%$ CI: 1.00-2.28) from acute versus overuse injury.
Among all sports, the likelihood of medical disqualification from acute injury was higher than that from overuse injury for girls' basketball (IPR: 2.85, $95 \%$ CI: $1.35-$ 5.98), girls' softball (IPR: 2.64, $95 \%$ CI: 1.05-6.62), and girls' soccer (IPR: $2.18,95 \%$ CI: 1.21-3.90). All other sports demonstrated no difference in the proportion of medical disqualification from acute versus overuse injury.

\section{Discussion}

This is the first study to compare acute and overuse injuries using a nationally representative sample of high school athletes participating in 5 boys' sports (football, soccer, basketball, wrestling, baseball) and 4 girls' sports (soccer, volleyball, basketball, softball). There was an average of 1341127 high school sports-related injuries per year, equating to an average of 153 injuries every hour, associated with the sports included in this study. In addition to the monetary toll an injury may take, 
Table 2 Injury Rates and Rate Ratios of Acute versus Overuse Injuries by Year, Gender, Sport, and Exposure Type

\begin{tabular}{|c|c|c|c|c|c|c|}
\hline \multirow[b]{2}{*}{ Variable } & \multirow[b]{2}{*}{ AEs } & \multicolumn{2}{|c|}{ Acute Injuries } & \multicolumn{2}{|c|}{ Overuse Injuries } & \multirow{2}{*}{$\begin{array}{l}\text { Injury Rate Ratio } \\
(95 \% \mathrm{Cl})\end{array}$} \\
\hline & & Number & $\begin{array}{l}\text { Rate } \\
\text { per } \\
10, \\
000 \\
\text { AEs }\end{array}$ & Number & $\begin{array}{l}\text { Rate } \\
\text { per } \\
10, \\
000 \\
\text { AEs }\end{array}$ & \\
\hline Total & 25261047 & 48585 & 19.2 & 3700 & 1.5 & $13.12(12.69,13.57)$ \\
\hline \multicolumn{7}{|l|}{ Year } \\
\hline 2006-07 & 1820367 & 4154 & 22.8 & 385 & 2.1 & $10.79(9.72,11.98)$ \\
\hline 2007-08 & 2077780 & 4323 & 20.8 & 343 & 1.7 & $12.60(11.29,14.07)$ \\
\hline 2008-09 & 2112479 & 3848 & 18.2 & 287 & 1.4 & $13.41(11.89,15.12)$ \\
\hline $2009-10$ & 1763241 & 3386 & 19.2 & 235 & 1.3 & $14.41(12.62,16.45)$ \\
\hline 2010-11 & 1762485 & 3271 & 18.6 & 230 & 1.3 & $14.22(12.44,16.26)$ \\
\hline 2011-12 & 1733895 & 3552 & 20.5 & 243 & 1.4 & $14.62(12.84,16.65)$ \\
\hline 2012-13 & 1874256 & 3925 & 20.9 & 220 & 1.2 & $17.84(15.58,20.44)$ \\
\hline 2013-14 & 1873729 & 3899 & 20.8 & 271 & 1.5 & $14.39(12.72,16.27)$ \\
\hline 2014-15 & 1723204 & 3557 & 20.6 & 207 & 1.2 & $17.18(14.94,19.77)$ \\
\hline 2015-16 & 1779940 & 3876 & 21.8 & 336 & 1.9 & $11.54(10.32,12.90)$ \\
\hline 2016-17 & 1602904 & 3190 & 19.9 & 234 & 1.5 & $13.63(11.94,15.57)$ \\
\hline 2017-18 & 1674494 & 3850 & 23.0 & 374 & 2.2 & $10.29(9.26,11.45)$ \\
\hline 2018-19 & 1732499 & 3754 & 21.6 & 335 & 1.9 & $11.17(9.99,12.49)$ \\
\hline \multicolumn{7}{|c|}{ Gender (all sports) } \\
\hline Male & 15566184 & 36685 & 23.6 & 2239 & 1.4 & $16.38(15.70,17.10)$ \\
\hline Female & 7965090 & 11900 & 14.9 & 1461 & 1.8 & $8.14(7.71,8.60)$ \\
\hline \multicolumn{7}{|c|}{ Gender (comparable sports) } \\
\hline Male & 7313633 & 9266 & 12.7 & 996 & 1.4 & $9.30(8.71,9.93)$ \\
\hline Female & 5819622 & 9781 & 16.8 & 1142 & 2.0 & $8.56(8.05,9.10)$ \\
\hline \multicolumn{7}{|l|}{ Boys' Sports } \\
\hline Football & 6317503 & 23584 & 37.3 & 1051 & 1.7 & $22.43(21.09,23.86)$ \\
\hline Soccer & 2298919 & 3663 & 15.9 & 379 & 1.7 & $9.66(8.70,10.74)$ \\
\hline Basketball & 2806929 & 3912 & 13.9 & 267 & 1.0 & $14.65(12.94,16.59)$ \\
\hline Wrestling & 1935048 & 3835 & 19.8 & 192 & 1.0 & $19.97(17.28,23.09)$ \\
\hline Baseball & 2207785 & 1691 & 7.7 & 350 & 1.6 & $4.83(4.31,5.42)$ \\
\hline \multicolumn{7}{|l|}{ Girls' Sports } \\
\hline Soccer & 2001410 & 4456 & 22.3 & 452 & 2.3 & $9.85(8.95,10.86)$ \\
\hline Volleyball & 2145468 & 2119 & 9.9 & 319 & 1.5 & $6.64(5.90,7.47)$ \\
\hline Basketball & 2189892 & 3687 & 16.8 & 378 & 1.7 & $9.75(8.77,10.84)$ \\
\hline Softball & 1628320 & 1638 & 10.1 & 312 & 1.9 & $5.25(4.65,5.93)$ \\
\hline \multicolumn{7}{|l|}{ Exposure Type } \\
\hline Competition & 6472178 & 28355 & 43.8 & 886 & 1.4 & $32.00(29.93,34.22)$ \\
\hline Practice & 17061395 & 20219 & 11.9 & 2814 & 1.7 & $7.19(6.91,7.47)$ \\
\hline
\end{tabular}

which can be upwards of $\$ 700$ per injury in direct medical costs, athletes can be subject to long-term physical and psychological sequelae (Knowles et al. 2007; Maffulli et al. 2010; Shuer and Dietrich 1997). The consequences of injury, when combined with the frequency of injury and rising sport participation numbers, represent a large burden on both the student athletes' health and the health care system.

Prior studies of collegiate and high school athletes have shown that females are at higher risk of overuse 


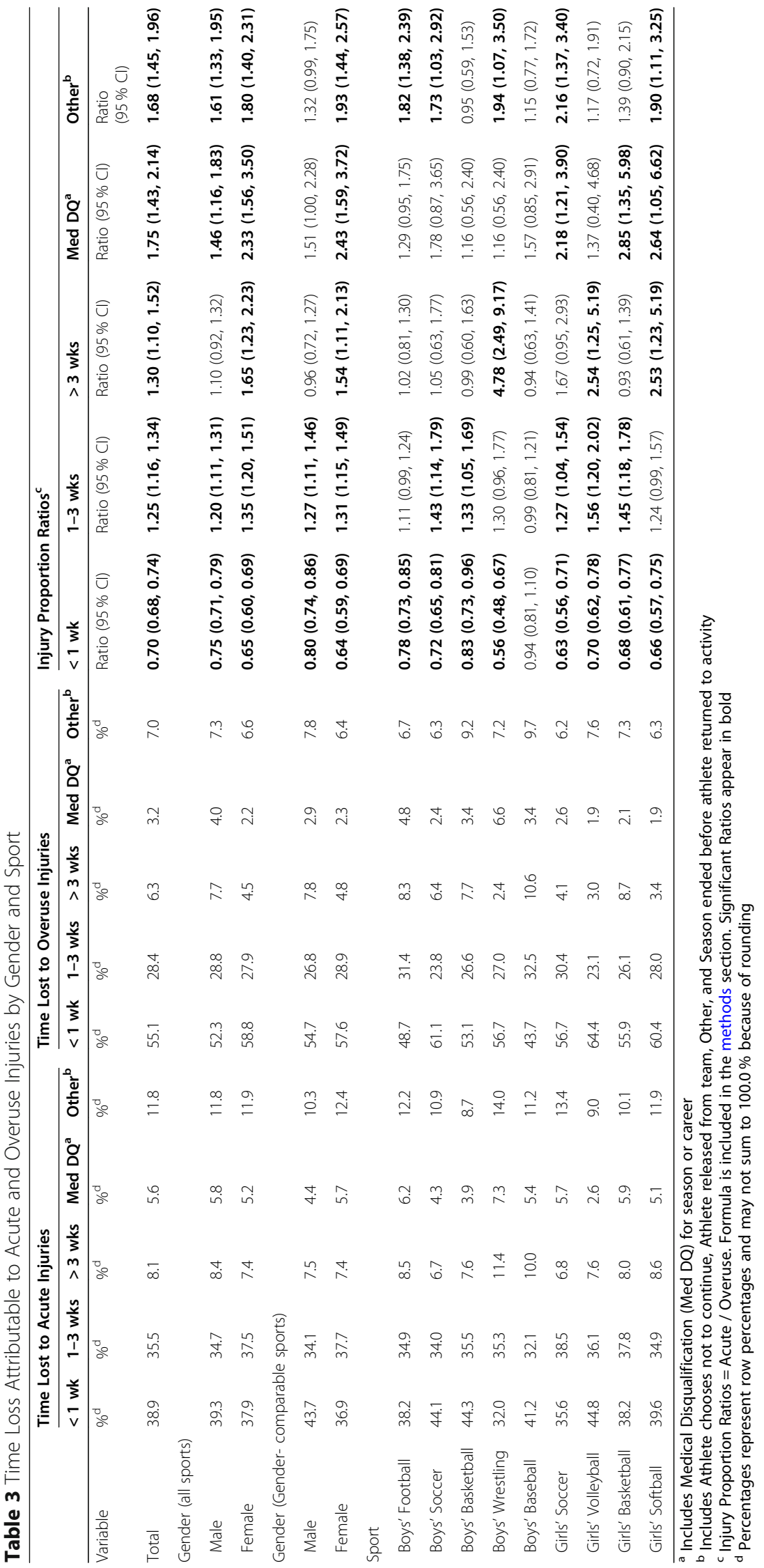


injury than males, with possible reasons cited as gender differences in biomechanics, coaching, or help-seeking behavior (Yang et al. 2012; Post et al. 2020; Roos et al. 2015). In concordance with this, when considering all 9 sports in this study, female athletes had a higher rate of overuse injury than males, while male athletes had a higher rate of acute injury. This was largely attributable to the disproportionately high rate of acute injury associated with football. When considering only gendercomparable sports, female athletes experienced higher rates of both acute and overuse injury than males, though males accounted for most acute and overuse injuries because of higher participation numbers. These findings underscore the potential benefit of implementation and evaluation of additional prevention measures in a gender- and sport-specific manner. In addition, acute injury prevention efforts in collision sports like football can have a large impact, where just a $1 \%$ decrease in occurrence equates to almost 70,000 injuries avoided nationwide per year.

Time loss associated with acute and overuse injuries demonstrated important differences. Acute injuries were less likely to cause $<1$ week of time loss than were overuse injuries for both male and female athletes. Acute injuries were more likely than overuse injuries to cause a time loss of 1-3 weeks or medical disqualification among both male and female athletes; this was also true among female (but not male) athletes for $>3$ weeks of time loss. These observed differences are most likely a result of the nature of these types of injury; while overuse injuries are the result of repetitive microtrauma with inadequate rest time for repair, acute injuries can result from greater forces resulting in injuries that may require longer healing time (Roos et al. 2014; DiFiori et al. 2014; Hubbard et al. 2008; Karladani et al. 2001). These results may also be due to the number of concussive injuries which often require $>1$ week of recovery time when following return-to-play protocols (Tamura et al. 2020). Although time loss due to some injuries may be inevitable, the development of training/competition schedules with adequate rest time built in and continued improvement of treatment protocols may lead to quicker return-toplay and reduce the number medical disqualifications for both acute and overuse injuries.

The lower extremities were the most common body site for both acute and overuse injuries in this study. While the sports included in this study may predispose to more injuries to the lower extremities than other body sites, this finding is in agreement with previous studies, which included swimming, gymnastics, and tennis in addition to many of the sports in the current study (Yang et al. 2012; Rechel et al. 2008; Roos et al. 2015). With approximately half of acute and two-thirds of overuse injuries occurring to the lower extremities, this has clear implications regarding where prevention efforts are needed. Acute injuries also commonly occurred in the head/face/neck region. This was largely attributable to concussions, which accounted for almost one-fourth of acute injuries. Sports-related concussions have been the focus of new laws and regulations during recent years. Although implementation of these laws led to increased recognition of concussions and therefore an increased reporting of concussions, preliminary research has shown a decline in the recurrent concussion rate within 3 years of law implementation that may be attributable to changes in return-to-play requirements (Yang et al. 2017). A similar public policy approach may help reduce other types of sports-related injury.

Prior research has reported that injury recurrence is more commonly attributable to an overuse mechanism, while new injuries are more likely a result of contact with another person (Welton et al. 2018). Our study was consistent with these findings, with a higher proportion (19\%) of overuse injuries being recurrent than among acute injuries (10\% were recurrent), and $90 \%$ of acute injuries being new injuries compared with $82 \%$ of overuse injuries being new. Previous studies have reported that an average of about $10 \%$ of sports injuries in high school each year are recurrent, which is similar to the proportions of recurrent injury in our study; $19 \%$ of overuse and $10 \%$ of acute injuries were recurrent (Welton et al. 2018; Powell and Barber-Foss 1999). Although the mechanism of injury likely plays a role in injury recurrence, rehabilitation strategies may also be a factor. Acute injuries may have better-defined timelines for healing and return-to-play based on diagnosis or severity, whereas recovery from overuse injuries may be more subjective in nature. The prevalence of recurrent injury in high school sports offers an opportunity for improved treatment strategies and rehabilitation techniques to reduce the likelihood of an injury occurring more than once. Future research should explore the causes of recurrent injuries, for example, whether they are due to poor technique, risk-taking by the athlete, or incomplete healing; this would allow development of targeted interventions to help prevent these injuries.

The type of exposure greatly influenced the risk of acute versus overuse injury. Overall, during competition, athletes were 32 times more likely to sustain an acute injury than an overuse injury, while during practice, they were only 7 times more likely. A prior study showed that practice injuries occur at lower rates than competition injuries, and this was attributed to competition having an increased speed of play and an increased likelihood for more forceful collisions (Rechel et al. 2008). In our study, the acute injury rate during competition was almost four times that during practice, while overuse injuries occurred at similar rates regardless of the type of 
exposure. This demonstrates that the overall difference between competition and practice injury rates is driven by acute injury occurrence.

\section{Study Limitations and Strengths}

This study has some limitations. Injuries must result in time loss from sports participation to be reported in $\mathrm{RIO}^{\mathrm{rm}}$ (except for fractures, concussions, dental injuries, and heat illness/injury); therefore, both acute and overuse injuries may be underreported because not all prevent an athlete from returning to play. Previous research showed that $50.8 \%$ of overuse and $29.8 \%$ of acute injuries among athletes from one NCAA Division 1 program resulted in no time loss (Yang et al. 2012). This issue may especially affect overuse injuries because they are progressive in nature. Additionally, overuse injuries may not be reported until a specific event causes time loss for an athlete, which may alter the categorization of these injuries to acute. Some sports that may predispose to more overuse injuries (track and field, swimming, etc.) were not included in this study because $\mathrm{RIO}^{\mathrm{m}}$ only captures injuries associated with these sports using convenience sampling. Overall, the definition of overuse injury has, historically, not been clearly defined. This may limit comparison between our study and those of other investigators. The lack of exposure data in $\mathrm{RIO}^{\mathrm{sin}}$ for some variables, such as diagnosis, body site injured, and athlete's year in school, precluded calculation of rates for these variables and is a limitation of this study. Despite these limitations, a strength of this study is that it utilized a large, nationally representative sample of injury and exposure data collected by ATs using strict data quality procedures. $\mathrm{RIO}^{\mathrm{m}}$ data have been used in more than one hundred peer-reviewed publications to-date, attesting to the strength and quality of this surveillance system and database. To our knowledge, this is the first study to compare characteristics of acute and overuse injuries at the national level. This study provides a foundation for additional studies that better define and quantify overuse injuries or compare acute and overuse injuries and associated risk factors within specific sports.

\section{Conclusions}

Acute injuries accounted for most high school sportsrelated injuries and occurred at a higher rate than overuse injuries in the 5 boys' sports (football, soccer, basketball, wrestling, baseball) and 4 girls' sports (soccer, volleyball, basketball, softball) studied. They also resulted in greater time loss from sports participation than overuse injuries and occurred at a much higher rate during competition than practice. Overuse injuries were more likely to be recurrent injuries than acute injuries, while acute injuries were more often new injuries. Attention to these differences between acute and overuse injuries can help inform improved athlete preparation (such as conditioning and strength training), treatment, rehabilitation, and schedules allowing for adequate rest time, which may reduce injuries and improve injury outcomes in high school athletics.

\section{Abbreviations}

AE: Athlete Exposure; AT: Certified Athletic Trainer; Cl: Confidence Interval; IPR: Injury Proportion Ratio; RIO: Reporting Information Online; RR: Rate Ratio; US: United States

\section{Acknowledgements}

None.

\section{Authors' contributions}

ER contributed to the conception and design of the study, conducted data analyses and contributed to interpretation of data; she drafted the article, approved the final version to be published, and agrees to be accountable for all aspects of the work. JY contributed to the conception and design of the study, acquisition of data, and interpretation of data; she reviewed and revised the article critically for important intellectual content, approved the final version to be published, and agrees to be accountable for all aspects of the work. SK conducted data analyses and contributed to interpretation of data; she reviewed and revised the article critically for important intellectual content, approved the final version to be published, and agrees to be accountable for all aspects of the work. CC contributed to the

conceptualization and design of the study and interpretation of data; she reviewed and revised the article critically for important intellectual content, approved the final version to be published, and agrees to be accountable for all aspects of the work. GS contributed to the conception and design of the study, acquisition of data, and interpretation of data; he reviewed and revised the article critically for important intellectual content, approved the final version to be published, and agrees to be accountable for all aspects of the work.

\section{Funding}

Author, Erin Ritzer, received a student scholar research stipend from the Child Injury Prevention Alliance while she worked on this study. The interpretations and conclusions in this article do not necessarily represent those of the funding organization. The funding organization was not involved in the design and conduct of the study; collection, management, analysis, and interpretation of the data; preparation, review, or approval of the manuscript; and decision to submit the manuscript for publication.

\section{Availability of data and materials}

Data analyzed in this study were from the High School RIO ${ }^{T M}$ surveillance system, which is managed by the Datalys Center for Sports Injury Research and Prevention. Data requests should be submitted to the Datalys Center.

\section{Declarations}

Ethics approval and consent to participate

This study was judged to be non-human research and approval was waived by the institutional review board at the authors' institution.

\section{Consent for publication}

Not applicable.

\section{Competing interests}

The authors declare that they have no competing interests.

\section{Author details}

${ }^{1}$ Center for Injury Research and Policy, Abigail Wexner Research Institute at Nationwide Children's Hospital, Columbus, OH, USA. ${ }^{2}$ Lake Erie College of Osteopathic Medicine, 5000 Lakewood Ranch Blvd, FL 34211 Bradenton, USA. ${ }^{3}$ Department of Pediatrics, The Ohio State University College of Medicine, 
Columbus, OH, USA. ${ }^{4}$ Datalys Center for Sports Injury Research and Prevention, 401 West Michigan Street, Suite 500, Indianapolis, IN, USA. ${ }^{5}$ Child Injury Prevention Alliance, Columbus, OH, USA.

Received: 9 May 2021 Accepted: 25 June 2021

Published online: 11 August 2021

\section{References}

Badgeley MA, Mcllvain NM, Yard EE, Fields SK, Comstock RD. Epidemiology of 10,000 high school football injuries: patterns of injury by position played. J Phys Act Health. 2013;10(2):160-9. PMID: 22821941.

Cuff S, Loud K, O'Riordan MA. Overuse injuries in high school athletes. Clin Pediatr (Phila). 2010;49(8):731-6. PMID: 20308195.

DiFiori JP, Benjamin HJ, Brenner JS, et al. Overuse injuries and burnout in youth sports: a position statement from the American Medical Society for Sports Medicine. Br J Sports Med. 2014;48(4):287-8. PMID: 24463910.

Hubbard TJ, Hicks-Little CA. Ankle ligament healing after an acute ankle sprain: an evidence-based approach. J Athl Train. 2008:43(5):523-9. PMID: 18833315.

Ingram JG, Fields SK, Yard EE, Comstock RD. Epidemiology of knee injuries among boys and girls in US high school athletics. Am J Sports Med. 2008; 36(6):1116-22. PMID: 18375784.

Karladani AH, Granhed H, Kärrholm J, Styf J. The influence of fracture etiology and type on fracture healing: a review of 104 consecutive tibial shaft fractures. Arch Orthop Trauma Surg. 2001:121(6):325-8. PMID: 11482464

Kerr ZY, Collins CL, Pommering TL, Fields SK, Comstock RD. Dislocation/ separation injuries among US high school athletes in 9 selected sports: 2005-2009. Clin J Sport Med. 2011;21(2):101-8. PMID: 21358499.

Kerr ZY, Comstock RD, Dompier TP, Marshall SW. The first decade of web-based sports injury surveillance (2004-2005 through 2013-2014): methods of the national collegiate athletic association injury surveillance program and high school reporting information online. J Athl Train. 2018;53(8):729-37. PMID: 30024769 .

Knowles SB, Marshall SW, Miller T, et al. Cost of injuries from a prospective cohort study of North Carolina high school athletes. Inj Prev. 2007;13(6):416-21. PMID: 18056320

Liller KD, Morris B, Yang Y, Bubu OM, Perich B, Fillion J. Injuries and concussions among young children, ages $5-11$, playing sports in recreational leagues in Florida. PLoS One. 2019;14(5):e0216217. PMID: 31091293.

Lundberg Zachrisson A, Ivarsson A, Desai P, Karlsson J, Grau S. Athlete availability and incidence of overuse injuries over an athletics season in a cohort of elite Swedish athletics athletes - a prospective study. Inj Epidemiol. 2020;7(1):16. PMID: 32362281.

Maffulli N, Longo UG, Spiezia F, Denaro V. Sports injuries in young athletes: longterm outcome and prevention strategies. Phys Sportsmed. 2010;38(2):29-34 PMID: 20631461.

Merkel DL. Youth sport: positive and negative impact on young athletes. Open Access J Sports Med. 2013:4:151-60. PMID: 24379720.

Post EG, Biese KM, Schaefer DA, et al. Sport-specific associations of specialization and sex with overuse injury in youth athletes. Sports Health. 2020;12(1):3642. PMID: 31724908

Powell JW, Barber-Foss KD. Injury patterns in selected high school sports: a review of the 1995-1997 seasons. J Athl Train. 1999:34(3):277-84. PMID: 16558577.

Rechel JA, Yard EE, Comstock RD. An epidemiologic comparison of high school sports injuries sustained in practice and competition. J Athl Train. 2008;43(2): 197-204. PMID: 18345346

Roos KG, Marshall SW. Definition and usage of the term "overuse injury" in the US high school and collegiate sport epidemiology literature: a systematic review. Sports Med. 2014;44(3):405-21. PMID: 24242858.

Roos KG, Marshall SW, Kerr ZY, et al. Epidemiology of overuse injuries in collegiate and high school athletics in the United States. Am J Sports Med. 2015:43(7):1790-7. PMID: 25930673.

Saper MG, Pierpoint LA, Liu W, Comstock RD, Polousky JD, Andrews JR. Epidemiology of shoulder and elbow injuries among United States high school baseball players: school years 2005-2006 through 2014-2015. Am J Sports Med. 2018;46(1):37-43. PMID: 29048928.

Schroeder AN, Comstock RD, Collins CL, et al. Epidemiology of overuse injuries among high-school athletes in the United States. J Pediatr. 2015;166(3):6006. PMID: 25444010

Shanley E, Rauh MJ, Michener LA, Ellenbecker TS. Incidence of injuries in high school softball and baseball players. J Athl Train. 2011;46(6):648-54. PMID: 22488191.
Shuer ML, Dietrich MS. Psychological effects of chronic injury in elite athletes [published correction appears in West J Med 1997 Apr;166(4):291]. West J Med. 1997;166(2):104-109. PMID: 9109326.

Swenson DM, Yard EE, Collins CL, Fields SK, Comstock RD. Epidemiology of US high school sports-related fractures, 2005-2009. Clin J Sport Med. 2010;20(4): 293-9. PMID: 20606515.

Tamura K, Furutani T, Oshiro R, et al. Concussion recovery timeline of high school athletes using a stepwise return-to-play protocol: Age and sex effects. J Athl Train. 2020;55(1):6-10. PMID: 31876456

Welton KL, Kraeutler MJ, Pierpoint LA, Bartley JH, McCarty EC, Comstock RD. Injury recurrence among high school athletes in the United States: a decade of patterns and trends, 2005-2006 through 2015-2016. Orthop J Sports Med. 2018;6(1):2325967117745788. PMID: 29318177.

Xiang J, Collins CL, Liu D, McKenzie LB, Comstock RD. Lacrosse injuries among high school boys and girls in the United States: academic years 2008-2009 through 2011-2012. Am J Sports Med. 2014;42(9):2082-8. PMID: 25053695.

Yang J, Tibbetts AS, Covassin T, Cheng G, Nayar S, Heiden E. Epidemiology of overuse and acute injuries among competitive collegiate athletes. J Athl Train. 2012;47(2):198-204. PMID: 22488286.

Yang J, Comstock RD, Yi H, Harvey HH, Xun P. New and recurrent concussions in high-school athletes before and after traumatic brain injury laws, 2005-2016. Am J Public Health. 2017:107(12):1916-22. PMID: 29048967.

Yard EE, Collins CL, Dick RW, Comstock RD. An epidemiologic comparison of high school and college wrestling injuries. Am J Sports Med. 2008;36(1):5764. PMID: 17932400.

Yard EE, Schroeder MJ, Fields SK, Collins CL, Comstock RD. The epidemiology of United States high school soccer injuries, 2005-2007. Am J Sports Med. 2008: 36(10):1930-7. PMID: 18628486

Participation in high school sports registers first decline in 30 years. National Federation of State High School Associations. September 2019. https://www. nfhs.org/articles/participation-in-high-school-sports-registers-first-decline-in-3 0-years/. Accessed June 202020

\section{Publisher's Note}

Springer Nature remains neutral with regard to jurisdictional claims in published maps and institutional affiliations.

Ready to submit your research? Choose BMC and benefit from:

- fast, convenient online submission

- thorough peer review by experienced researchers in your field

- rapid publication on acceptance

- support for research data, including large and complex data types

- gold Open Access which fosters wider collaboration and increased citations

- maximum visibility for your research: over $100 \mathrm{M}$ website views per year

At BMC, research is always in progress.

Learn more biomedcentral.com/submission 